\title{
ARCHITECTURAL PRACTICING IN THE ERA OF GLOBALIZATION. (SAUDI MARKET AS A CASE STUDY)
}

\author{
Ibrahim N. A. Al-Bukhari ${ }^{1}$ and Ahmed M. A. Shehata ${ }^{2}$ \\ ${ }^{1}$ Chair of Islamic Architecture Department Collage of Engineering \& Islamic Architecture - \\ Umm Al-Qura University \\ ${ }^{2}$ Professor of Urban \& Environmental Design Islamic Architecture Department \\ Collage of Engineering \& Islamic
}

\begin{abstract}
In the era of free trade and open markets, international consultant firms started to take over the local markets. Local graduates are required to acquire certain skills and knowledge to compete in their local markets with the international graduates. Local architectural teaching institutes are required to equip their graduates with the needed skills and knowledge. Gulf construction and design market is one of the biggest markets in the world. Saudi Arabia, with its 646.44 billion Dollar GDB, considered as the biggest market in the Gulf area. The Saudi vision of 2030 concentrates on economical sustainability and developing citizens. In this regard, this research investigates the competitiveness of the Saudi educational outputs in the era of globalization and open markets. To achieve its objectives, the research analyzes the different scopes of practicing architecture specially in the design consultation field. International design firms working in the GCC counties and their required skills for positions were presented and analyzed. Moreover, educational architectural curriculums were investigated and tested against the required skills by international firms. The paper concluded with suggestions regarding to architectural programs and their curriculums that will enable Saudi graduates to fulfil the international consultation market required qualifications and skills.
\end{abstract}

Keywords: Saudi 2030 Vision - Educational Outputs - Architectural Practice Competitiveness.

\section{INTRODUCTION:}

Human capital is a vital factor in the success of any substantial development. One of the most significant assets of any society is its lively and vibrant youth. While many developed societies are concerned with aging populations, more than half of the developing societies' population is below the age of 25 years. It is important for developing countries to take advantage of this demographic dividend by harnessing youth's energy and providing them by the required skills.

In a world without borders, achieving desired rate of economic growth require an environment that attracts the necessary skills and capabilities both from within the local society and beyond national borders. This means building, attracting and retaining the finest local minds, and provide them with all they need. One of the Gulf state vision aspects is make use of the local as well as the foreign working force to contribute to economic development and attract additional foreign investment. The 2030 Saudi vision handled this issue and put objectives and strategies to ensure sustainable economy that works for Saudi citizens.

\section{Saudi Construction Market Profile:}

The construction industry is showing strong growth rates through the last few years. Charts in Figures 1 to 4 shows some of the most important indicators about the industry potential and 
market size of construction. It should be noted that the easy accessibility to building materials, such as cement, doors, and windows in the domestic market, are positive indicators for the construction industry. The growth in the construction industry has led to a wide array of job opportunities for both domestic and foreign job seekers. Despite the anticipated budget deficit of USD 87 billion in 2016, construction projects are expected to be completed without any hindrances. The residential sector is also expected to grow significantly, as the rapid population growth (population is expected to reach $\sim 37$ million over the next 10 years) in the Kingdom has stemmed a need for $\sim 3$ million housing units by 2025. (Global research, 2016 and Turner \& Townsend 2016)

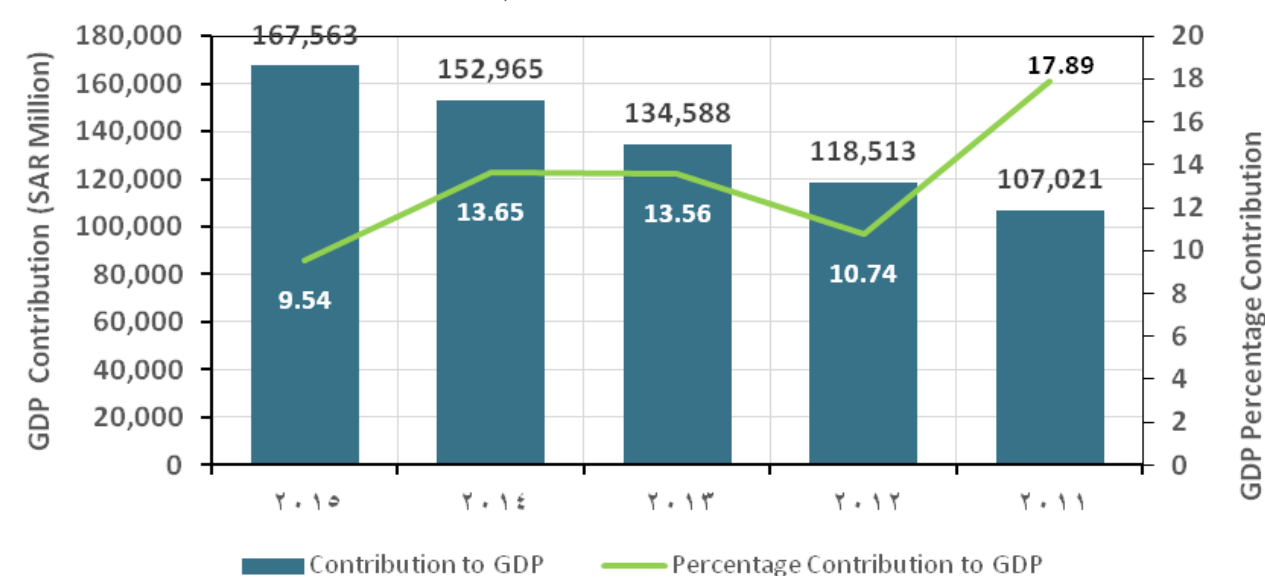

Figure: 1: Construction Sector Contribution to GDP (2011-2015) (Saudi Arabian Monetary Agency 2015)

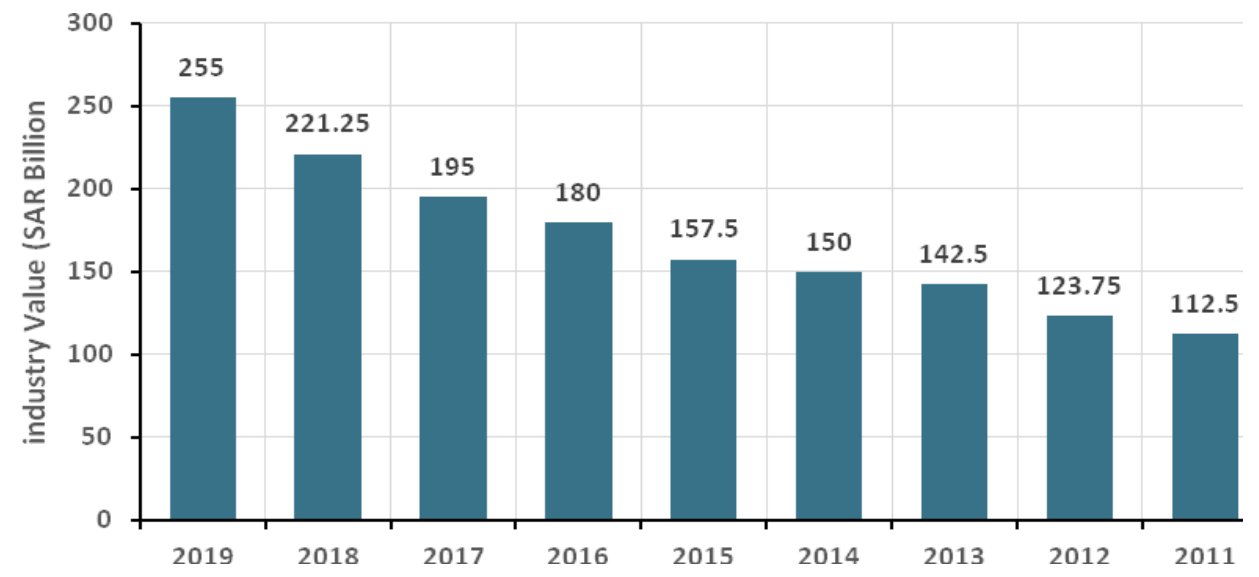

Figure: 2: Construction Sector Value in KSA (2011-2019F) (U.K Trade \& Investment 2016)

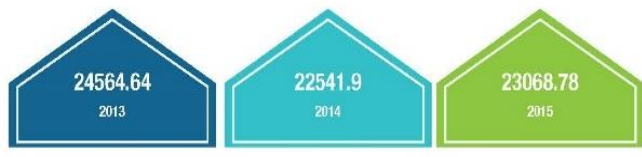

Figure: 3: Building Construction Contracts Awarded 2013-2015 (USD Million) (Jeddah Chamber, 2016)

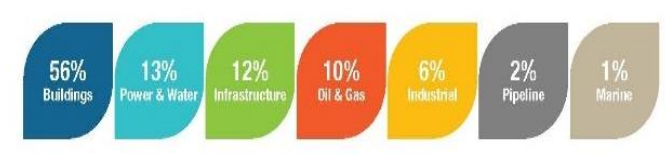

Figure: 4: Sector-wise Construction Budget Distribution (2015) (Jeddah Chamber, 2016)

\subsection{Architecture Practicing in GCC:}

Architecture record annual statistics of the top twenty firms in the world showed that, $65 \%$ of the twenty top firms get more than $45 \%$ of their revenue out of practicing architecture design while $45 \%$ of them coming from architectural engineering consultations. Three of these firms gets more than $40 \%$ of their revenue from international practicing. Results of the top twenty firms' revenues distribution are presented in figures 5, 6 and 7. (Architectural Record, 2016) 


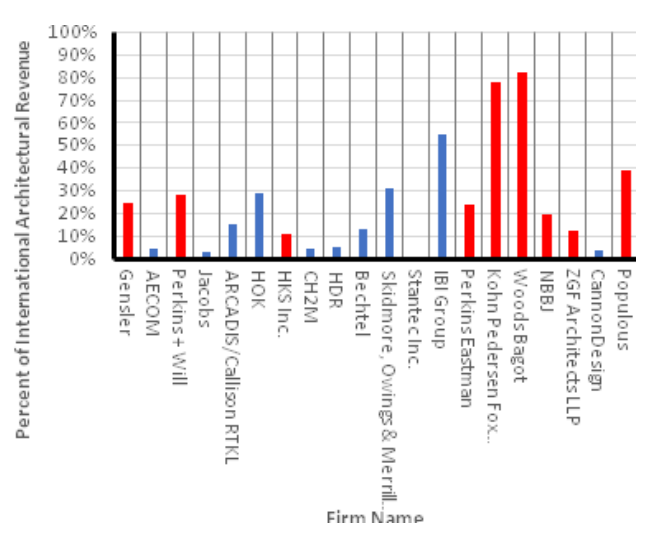

Figure: 5 Percent of International Revenue of Architectural Firms

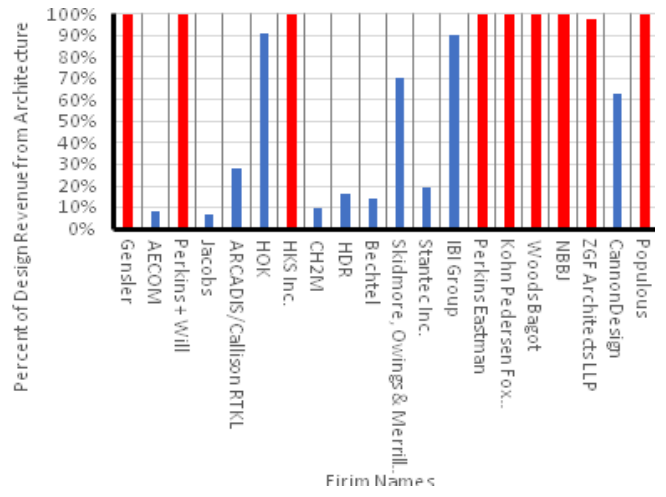

Figure: 6 Percent of Design Revenue from Architecture

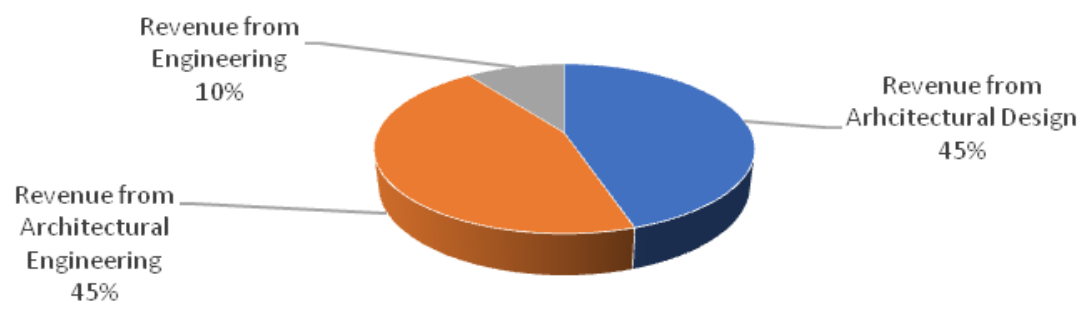

Figure: 7 Top Twenty Firms in 2016 Survey Revenue Distribution

\subsection{Required Skills and Knowledge:}

Surveying Job postings of the top firms that gets their revenue from practicing architecture, shows that the required skills can vary based on the job but in general key skills can be classified into the following categories: (LinkedIn, 2017)

\subsubsection{Codes Knowledge:}

knowledge of codes and ability to interpret them and ensure designs meet codes is an essential aspect of any architecture job.( Vanessa,2017)

- Architectural - Leadership in Energy \& Environmental

Codes

- Building Codes

\subsubsection{Technical Design Skills}

$$
\text { Design (LEED) }
$$

- Zoning Codes

Using computer programs and processes are the key skills for architectural design:
- Technical Vision
- AutoCAD
- Revit
- Model Making
- Design Concepts
- Design to
Delivery
- Industrial Design
- Computer Aided Design (CAD)
- Sustainable Design - Specifications
- Computer
- Drafting
- Plans
- Rendering Processing
ruction Skills

\subsubsection{Building and Construction Skills}

Awareness of requirement and process of different kind of buildings and construction, their settings and its surroundings require the following skills:

- Building

Construction

- Industrial Design

- Retail
- Building Systems

- Installation

- Rehabilitation
- Construction Administration

- New Construction

- Renovation

\subsubsection{Project Management Skills:}

The following skills needs to be pursued and developed through study and practice on real projects:
- Analysis
- Conceptualization
- Client Relations
- Collaboration
- Design to Delivery

- Budgeting

- Communication

- Finance
- Construction Documents

- Preservation

- Residential
- Coordination

- Legal

- Management 
- Problem Solving

- Specifications

- Solving Complex Problems
- Project

Management

- Building Codes

- Seeing Big Picture Results
- $\quad$ Scheduling

- Architectural Codes

- Leadership in Energy \& Environmental Design (LEED)

Moreover, Job sites like LinkedIn statics shows that job postings for architects are almost more than half of the engineering job postings (shown in figure 8). It shows also that knowledge of computer software like AutoCAD, Sketch UP, Revit and Photoshop are essential skills specially for fresh graduates. Figure 9 shows the distribution of the key skills where architectural design comes first then computer software. (LinkedIn, 2017)

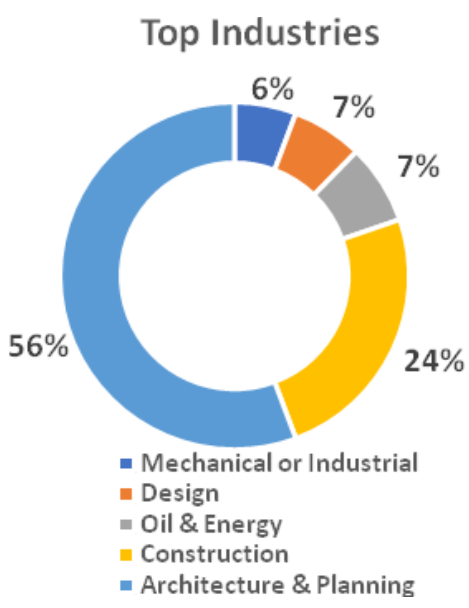

Figure: 8 Insights about Architect - Top Gulf Consultant members on LinkedIn

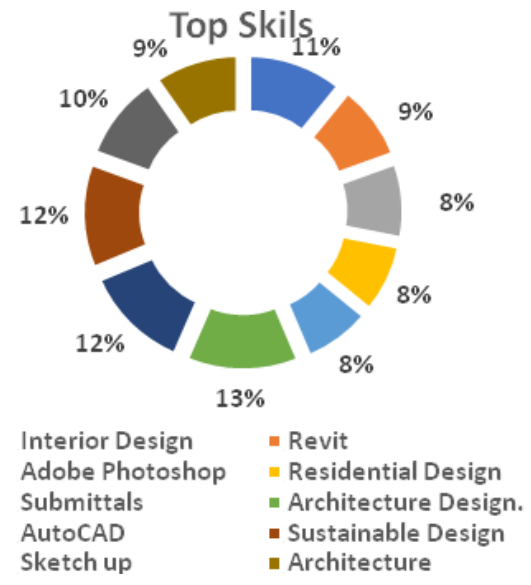

Figure: 9 Top skills - Required by Architecture Consultant members on LinkedIn

Required experience and skills vary based on the job responsibilities and description. Alison Doyle in her article about most wanted architectural skills argued that accreditation is more important to architects than being licensed. Moreover, she claimed that LEED accreditation is the most wanted skill for different firms. Figures 10 and 11 illustrates the most wanted skills as per statistics of Job Seeking site. (Alison 2017)

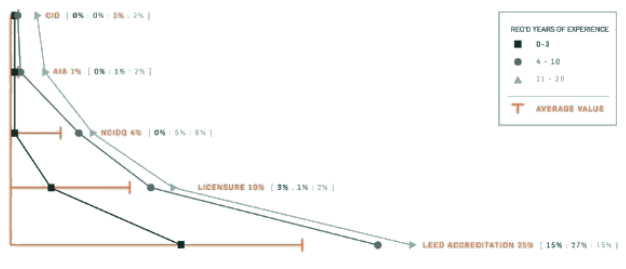

Figure: 10 Architecture licensure verses Accreditation.

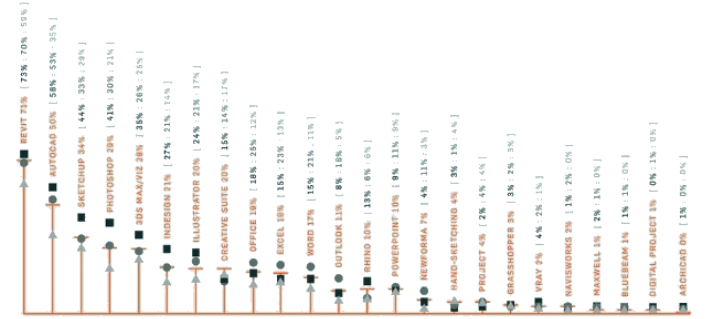

Figure: 11: Key skills rated according to job postings.

\section{Th Saudi Vision of 2030:}

The second axe of the 2030 Saudi vision considers achieving thriving economy. The objectives that formulate this axe is consolidated in the learning for working. It stated that this would be achieved through investing in educating and training the young men and women to be equipped for the jobs of the future. It is the aim that Saudi youth, wherever they live, to enjoy higher quality, multi-faceted education. Efforts will be doubled to ensure that the outcomes of the Saudi education system are in line with market needs. launching the National Labor Gateway (TAQAT) is part of these efforts. Proposed sector councils will precisely determine the skills and knowledge required by each socio-economic sector. Expanding in vocational training will drive forward economic development. Scholarship opportunities will be steered towards prestigious international universities and will be awarded in the fields that serve the national priorities. Innovation in advanced technologies and entrepreneurship will be in the focus of education. (National Transformation Program 2020, 2017)

4. SAUDI ARCHITECTURAL EDUCATIONAL PROGRAMS: 
The architecture schools within the Kingdome were surveyed. Table (1) summaries the results of curriculum of the surveyed architectural educational institutes in Saudi Arabia. The survey shows that there are eighteen universities that teach architecture in the kingdom of Saudi Arabia. While 28\% out of these eighteen are private universities, $22 \%$ of them are graduating only female architects. Basic results showed that the study plan of these universities varies widely in their curriculum areas, position statements, program objectives and contents. Table 1 also shows big differences in number of elective courses and their topics. While Hail and Umm Al-Qura universities does not have any elective courses, Taibah university has eight elective course and the average of the rest is three courses. The most critical remark was the big difference in number of design courses and this of course affects the complexity of their projects. King Faisal, Prince Sultan and Taibah offer only three courses in addition to the graduation project. While king Fahd university students attend 10 design studios. Results also shows that only half of the surveyed schools gives a deep and detailed building science courses. (Anita Joseph, 2017)

Table 1 : Contents of Curriculums of Surveyed Universities:

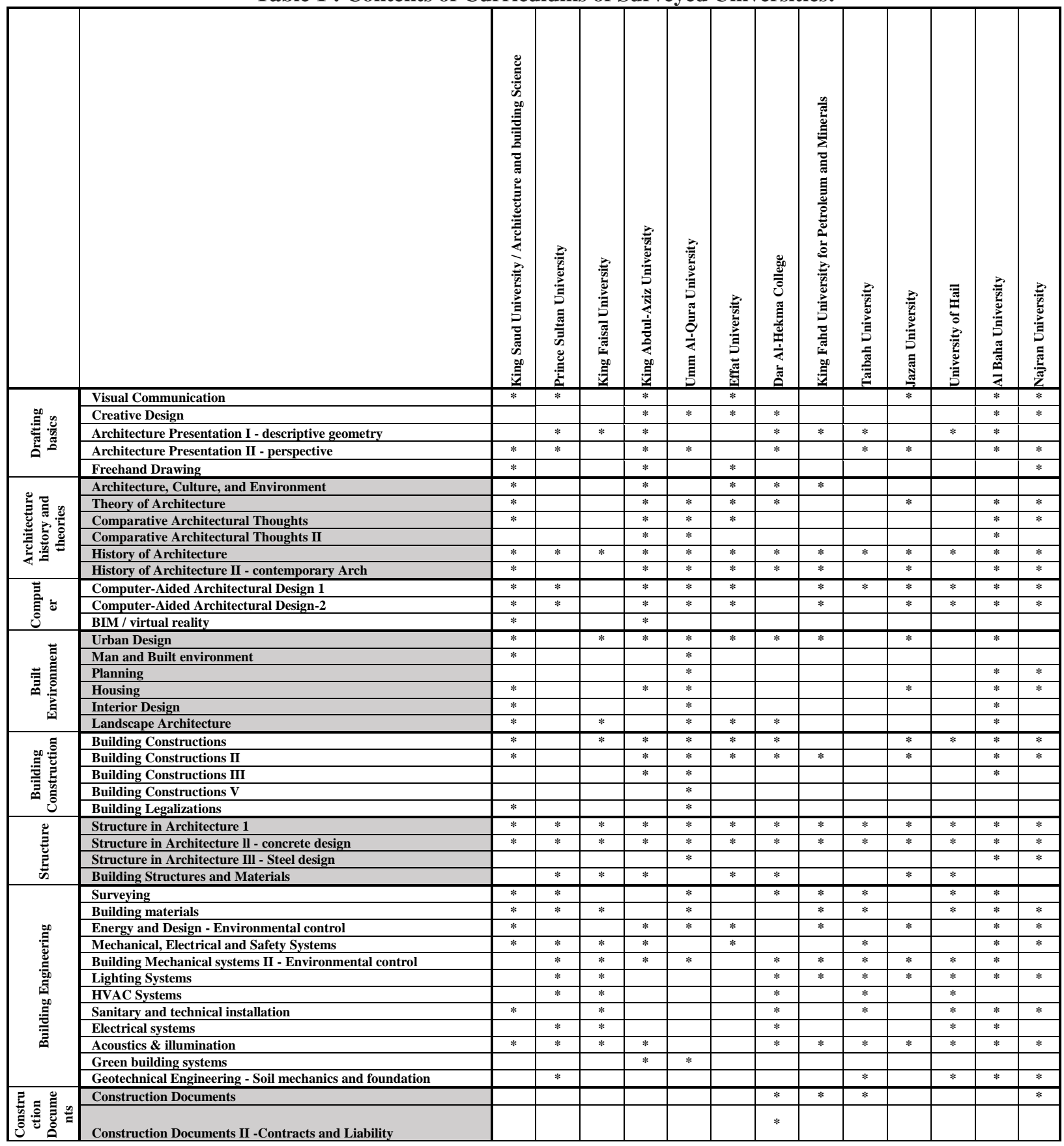




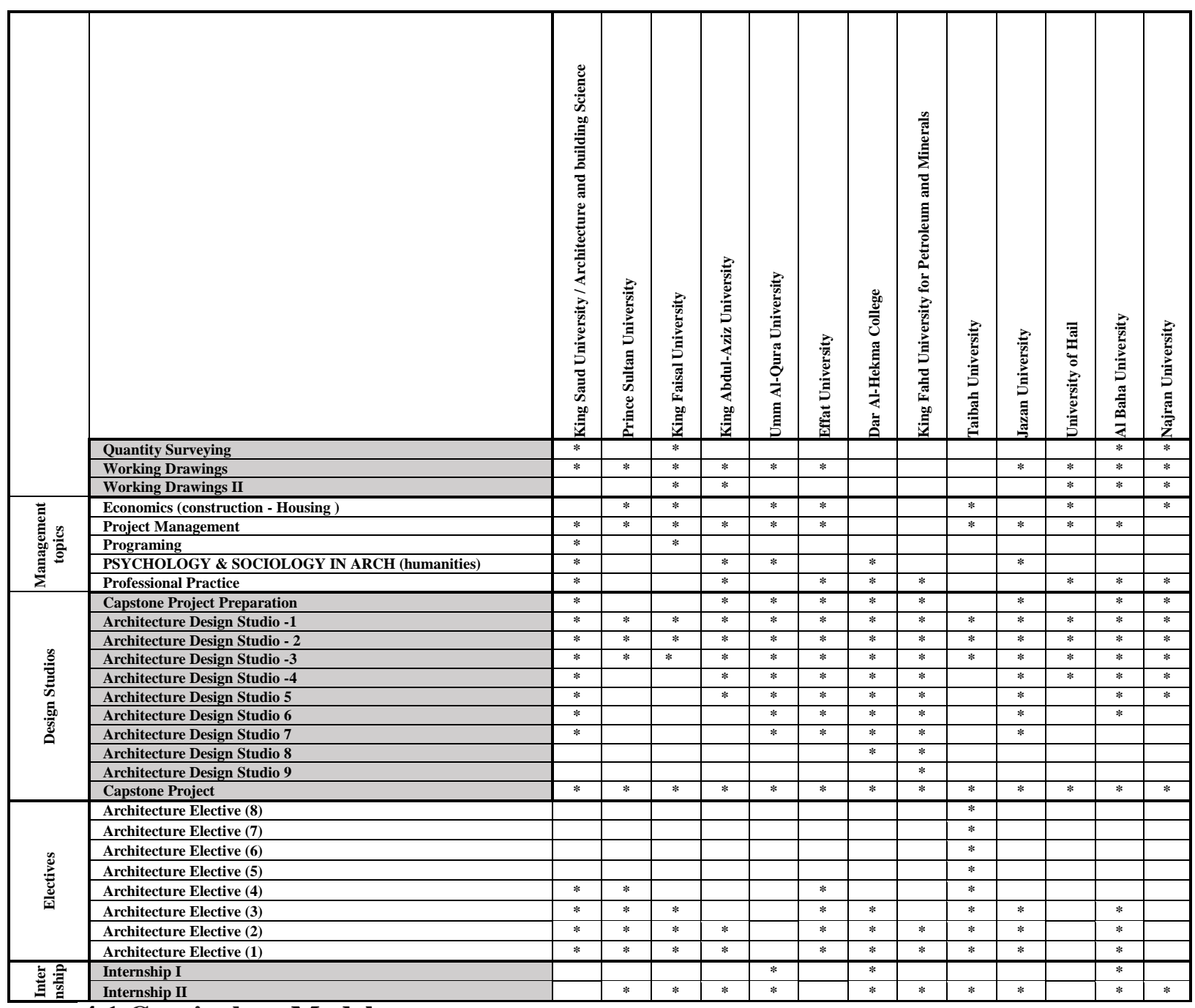

4.1.Curriculum Models,

King Saud, King Fahd and King Abul-Aziz universities are the oldest and have the most developed curriculum and constitutes the reference for the rest of the architecture universities. Their curriculum is based on a hybrid model that started with the Bauhaus generated American model, then transformed after series of developments into unique programs. Students are enrolled for three different phases:

- General studies: It aims at developing their basic design skills, drawing abilities, while assimilating theoretical knowledge related to the built environment disciplines.

- Intermediate phase (Junior): In this phase, core applied and theoretical knowledge is developed and advanced architectural engineering skills is being developed.

- Professional phase (senior): This phase aims at building environmental and global awareness and developing management skills. There are university requirements, college requirements, and departmental requirements. Most of the university requirements are required in the first year.

All the other universities curriculums are different modified versions of this curriculum. (Anita Joseph, 2017).

\subsection{Position Statements,}

Some of the surveyed curriculums were oriented to environmental studies where sociology and human culture impact on social and physical environment and their design related courses are in the core of the courses, while in other cases engineering and building science where courses of mechanical and electrical in addition to structure and design courses are in the core courses, while the rest are elective courses. In the third orientation, architecture design pedagogy which is supplemented with history and theory courses.

All the surveyed curriculums were split somehow into three different phases: 
- Introductory Stage; one or two years dedicated to offering students basic science, basic design, and the development of their imagination and conceptual skills

- Intermediate Stage; after the introductory phase, for two to three-years stage, students are specialized in one of the core disciplines mentioned earlier in this section: architecture, environmental design, or construction engineering.

- Professional Stage; a one year of professional studies that include courses in professional practice, building economics, and the graduation project.

\subsection{Programs' Objectives}

Some of the surveyed programs aims to graduates architects with extra engineering background the others aims to graduates architects with humanities and environmental background. They all have a dose of building science background. The overall objectives vary according to the positon statement of each program. But in general, the objectives can be rounded in the following points:

- Provide students with the knowledge and skills necessary for the practice of architecture.

- Prepare graduates who can contribute the development and improvement of the Saudi local natural and built environment.

- Develop the students' intellectual awareness of the physical and spiritual factors constraints and their impact on the designed environment.

- Preparing future generations of architects who can propose design and planning solutions for local problems, assimilate environmental and technological factors that influence the building industry, and manage the design and execution of buildings

\section{Conclusion and Recommendations:}

The research proved that key skills defined by professional market are almost aligned by the educational trends within the educational architecture schools in the Kingdome despite that the research did not investigate the details of courses' contents. It also showed that there is a big variation in the given dose of many knowledge fields like design, computer and building science.

Building Construction and computer application in addition to construction management axes needs to be enhanced in terms of contents and number of contact hours. This can be achieved through obligatory courses or elective ones to match the required key skills of the job postings.

The research recommends that curriculum of architecture schools within the Kingdome needs to be standardized through efforts to be led by the education ministry. This will ensure maintaining minimum standard skills and knowledge of the graduated architects. Moreover, Curriculum of architecture schools within the Kingdome periodically must be updated aligned with the professional market required key skills.

It is recommended that specialized diplomas that give professional architects deeper and more specialized knowledge in key fields like sustainability accreditation and building codes and projects management should be facilitated by architecture educational institutes within the Kingdome in cooperation with the Saudi professional societies.

\section{REFERENCES}

1. Alison Doyle, Architect Skills List, The balance, <https://www.thebalance.com/architectskills-list-2063730>, accessed in 30/6/2017.

2. Anita Joseph, College and universities in Saudi Arabia, <http://get2knowsaudiarabia.blogspot.com.eg/2010/08/top-colleges-and-universities-insaudi.html >, accessed in 30/6/2017.

3. Architectural Record, 2016 Top 300 Architecture Firms, <http://www.architecturalrecord.com/Top300/2016-Top-300-Architecture-Firms-1>, accessed in 30/6/2017.

4. Global Research, The GCC consulting Market in 2017 Report, Source information global Ltd., Dubai, 2016.

5. Jeddah Chamber, Saudi Arabia - Industrial Sector Overview Report, 2016. 
6. LinkedIn, Architect-Gulf Consultant Jobs, Insite about architect - Gulf Consult members on LinkedIn, <https://www.linkedin.com/userp/title/architect-at-gulf-consult $>$, accessed in 30/6/2017

7. LinkedIn, Architect-Gulf Consultant Jobs, Insite about architect members on LinkedIn, <https://www.linkedin.com/title/site-architect>, accessed in 30/6/2017.

8. National transformation Program, 2020, 2016.

9. Saudi Vision, 2030.

10. Saudi Arabian Monetary Agency, Fifty First Annual Report 1436 H - 2015, 2015.

11. Turner \& Townsend, International Construction Market Survey Report, Turner \& Townsend, 2016.

12. Vanessa Quirk, Want to Land a Job at One of the Top 50 Architecture Firms? Here Are the Skills You Need to Have, http://www.archdaily.com/527556/want-to-land-a-job-atone-of-the-top-50-architecture-firms-here-are-the-skills-you-need-to-have\#_=, accessed in July 2017.

13. U.K Trade \& Investment, Sector briefing-Construction Opportunities in Saudi Arabia Report, Crown Publisher, 2016. 